\title{
POTENSI DAUN PALA (Myristica fragrans Houtt) SEBAGAI SUMBER FENOLIK
}

\author{
Muammar Fawwaz ${ }^{1}$, Siti Nurdiansyah A, Muzakkir Baits \\ Fakultas Farmasi, Universitas Muslim Indonesia \\ ${ }^{1}$ muammar.fawwaz@umi.ac.id
}

\begin{abstract}
Phenolic is a compound that having an aromatic ring with one or more hydroxyl groups. Phenolic compounds in foods can be grouped into simple phenols and folic acid. This study aimed to determine the total phenolic content of the leaf extract of nutmeg (Myristica fragrans Houtt). Leaves of nutmeg extracted using $70 \%$ ethanol, then the extract conducting qualitative analysis by reaction with $\mathrm{FeCl}_{3}$ as specific reagent. The result of this reaction is green solution, it means there are phenolic compound in the extract. The quantitative process of total phenolic was analyzed by UV-Vis spectrophotometry. A comparison used in this analysis is gallic acid; it is a standard reference in the determination of total phenolic content. Sample measured at a wavelength of $860.7 \mathrm{~nm}$, which is the maximum wavelength of gallic acid. Total average content of phenolic is 183.56-mgGAE/g extract. The ethanol extract of nutmeg's leaves have high total phenolic content, which means it is potential as antioxidant.
\end{abstract}

Keywords: Nutmeg leaf, total phenolic, UV-Vis Spectrophotometry

\section{PENDAHULUAN}

Indonesia memiliki sumber daya genetik pala yang besar dengan pusat keragaman tanaman yang berada di kepulauan Maluku. Keragaman tanaman tertinggi ditemukan di Pulau Banda, Siau, dan Papua (Hadad dan Hamid, 1990). Sebagai pusat keragaman genetic (center of diversity), Indonesia harus mengambil peran yang lebih besar dalam pengelolaan, pengembangan, dan pemanfaatan tanaman ini. Pala sebagai sumber daya pertanian, perlu dikelola dan dimanfaatkan secara optimal guna mendukung pembangunan pertanian Indonesia yang berkelanjutan.

Daun pala mengandung minyak atsiri, senyawa utama minyak atsiri pada daun pala adalah myristicin (Puslitbang Perkebunan 2014). Minyak atsiri yang berasal dari biji dan fuli pala banyak digunakan untuk industry obat-obatan, parfum dan kosmetik.

Pala dikenal sebagai tanaman rempah yang memiliki nilai ekonomis dan multiguna karena setiap bagian tanaman dapat dimanfaatkan dalam berbagai industri. Daun pala merupakan salah satu bagian tanaman yang belum banyak termanfaatkan. Rastuti et al. (2013) memaparkan bahwa senyawa yang terkandung pada daun pala diantaranya alkaloida, triterpenoid, tanin, dan 2 flavonoid (Rastuti et al., 2013).

Komponen flavonoid yang terdapat pada daun pala menunjukkan keberadaan senyawa fenolik, sehingga perlu untuk dilakukan penelitian mengenai kandungan fenolik total pada ekstrak daun pala. Komponen fenolik ini penting mengingat peranannya yang besar dalam pengobatan dan pencegahan timbulnya penyakit termasuk sebagai antioksidan.

\section{METODE PENELITIAN}

A. Pengabilan dan Pengolahan Sampel

Pengambilan sampel daun pala (Myristica fragrans Houtt) di Kota Ambon, dengan cara mengambil daun yang masih segar kemudian dibersihkan dari kotoran yang melekat pada daun menggunakan air mengalir. Daun yang telah dibersihkan kemudian di gunting-gunting, dirajang dan diangin-anginkan selama beberapa hari (tidak boleh terkena sinar matahari langsung). Setelah kering, sampel diserbukan dan siap diekstraksi.

\section{B. Metode Ekstraksi}

Serbuk daun pala ditimbang 100 gram, dimaserasi menggunakan pelarut etanol 70\%, dibiarkan selama 3 hari dalam wadah tertutup dan terlindung dari cahaya matahari langsung sambil diaduk secara periodik, setelah 3 x 24 jam dilakukan penyaringan dan ampasnya dimaserasi kembali dengan cairan penyari yang baru. Maserasi dilakukan sebanyak 3 kali dan diperoleh ekstrak etanol cair. Hasil penyarian yang diperoleh kemudiaan diuapkan menjadi ekstrak kental.

\section{Analisis Kualitatif}

Senyawa golongan fenolik dapat dideteksi dengan menggunakan $\mathrm{FeCl}_{3} 1 \%$. Dimana pengujiannya yaitu sebanyak 1 gram sampel dilarutkan dengan etanol $70 \%$. Larutan yang dihasilkan diambil sebanyak $1 \mathrm{~mL}$ kemudiaan ditambahkan 2 tetes larutan $\mathrm{FeCl}_{3}$. Terbentuknya warna hijau atau hijau kebiruan menunjukkan adanya senyawa fenolik dalam sampel. 


\section{Analisis Kuantitatif}

1. Pembuatan larutan induk asam galat

Larutan standar asam galat $1000 \mathrm{ppm}$ dibuat dengan cara menimbang $5 \mathrm{mg}$ asam galat dilarutkan dengan etanol $70 \%$ p.a. hingga volume $5 \mathrm{~mL}$.

2. Pembuatan larutan $\mathrm{Na}_{2} \mathrm{HCO}_{3} 7 \%$

Sebanyak $1,75 \mathrm{~g} \mathrm{Na}_{2} \mathrm{HCO}_{3}$ ditambah $15 \mathrm{~mL}$ air suling, kemudian dididihkan sampai serbuk $\mathrm{Na}_{2} \mathrm{HCO}_{3}$ larut sempurna. Setelah itu didiamkan selama 24 jam, disaring dan diencerkan dengan air suling sampai volume $25 \mathrm{~mL}$.

3. Penentuan $\lambda_{\text {maks }}$

Penentuan panjang gelombang maksimum asam galat dilakukan dengan mengukur larutan asam galat 25 ppm pada range panjang gelombang 845-875 nm. Panjang gelombang $860.7 \mathrm{~nm}$ menunjukkan absorbansi maksimum sehingga merupakan panjang gelombang maksimum asam galat.

4. Pembuatan kurva baku asam galat

Dibuat deret konsentrasi 20, 30, 40, 50, dan $60 \mathrm{ppm}$ dari larutan induk, kemudian masingmasing dipipet $0,3 \mathrm{~mL}$ dan ditambahkan $1,5 \mathrm{~mL}$ reagen Folin-Ciocalteu lalu digojok, didiamkan selama 3 menit. Setelah itu ditambahkan 1,2 mL larutan $\mathrm{Na}_{2} \mathrm{HCO}_{3} 7 \%$ digojok homogen, kemudian didiamkan selama 10 menit pada suhu kamar. Semua larutan diukur absorbansinya pada panjang gelombang 860,7 nm, kemudian dibuat kurva kalibrasi dengan menggunakan persamaan regresi linier.

\section{HASIL DAN PEMBAHASAN}

\section{A. Hasil Penelitian}

Tabel 1. Hasil pengujian kualitatif senyawa fenolik ekstrak etanol Daun Pala

\begin{tabular}{cccc}
\hline Sampel & Pereaksi & Warna & Ket \\
\hline $\begin{array}{c}\text { Ekstrak Etanol } \\
\text { daun Pala }\end{array}$ & $\mathrm{FeCl}_{3}$ & Hijau & $(+)$ \\
\hline
\end{tabular}

Tabel 2. Kurva kalibrasi larutan standar asam galat

\begin{tabular}{cc}
\hline Konsentrasi $(\boldsymbol{\mu g} / \mathbf{L})$ & Absorbansi \\
\hline 20 & 0.315 \\
30 & 0.436 \\
40 & 0.575 \\
50 & 0.707 \\
60 & 0.892 \\
\hline
\end{tabular}

$y=0.0143 x+0.015$

Tabel 3. Perhitungan kadar rata-rata asam galat ada ekstrak etanol daun pala menggunakan spektrofotometri UV-Vis

\begin{tabular}{ccccc}
\hline Replikasi & Absorbansi (Y) & $\begin{array}{c}\text { Kandungan } \\
\text { FenolikAwal } \\
\text { (mg/L) }\end{array}$ & $\begin{array}{c}\text { Kandungan Fenolik } \\
\text { (mg GAE/g Sampel) }\end{array}$ & $\begin{array}{c}\text { Rata-rata Kandungan } \\
\text { Fenolik (mg GAE/g } \\
\text { Sampel) }\end{array}$ \\
\hline I & 0,567 & 38,601 & 193,005 & \\
II & 0,527 & 35,804 & 179,02 & 183,565 \\
III & 0,526 & 35,734 & 178,67 & \\
\hline
\end{tabular}

\section{B. Pembahasan}

Senyawa fenolik merupakan senyawa yang bersumber dari beragam tumbuhan. Senyawa ini mempunyai ciri, yaitu cincin aromatic yang mengandung satu atau dua gugus $\mathrm{OH}$. Senyawa fenolik di alam terdapat sangat luas mempunyai variasi struktur yang luas, mudah ditemukan di semua tanaman, daun, bunga dan buah. Ribuan senyawa fenolik di alam telah diketahui strukturnya antara lain flavonoid, fenol monosiklik sederhana, fenil propanoid, polifenol (lignin, melanin, tannin), dan kuinon fenolik (Fauzia, 2008).

Metode ekstraksi yang digunakan pada penelitian ini adalah maserasi, dimana ekstraksi merupakan salah satu langkah awal dalam melakukan penyiapan sampel. Metode ini juga sederhana, mudah dan tidak menggunakan proses pemanasan serta dilihat dari simplisia yang digunakan berupa daun yang memiliki tekstur lunak. Pelarut yang digunakan untuk ekstraksi sampel daun pala (Myristica fragrans Houtt) yaitu etanol 70\%. Pemilihan etanol 70\% sebagai pelarut bertujuan untuk mengekstraksi senyawa-senyawa yang bersifat polar dan non polar. Senyawa fenolik dapat terlarut oleh pelarut seperti etanol karena mempunyai gugus hidroksil (Ukieyanna, 2012). Etanol 70\% mampu mengekstrak senyawa fenolik lebih banyak dari pada etanol dengan kemurnian yang tinggi (Bimakr, 2010).

Ekstrak yang diperoleh dilanjutkan dengan uji kualitatif untuk memastikan ada tidaknya senyawa fenolik dalam ekstrak daun pala. Ekstrak yang dilarutkan dengan etanol 70\%, larutan yang dihasilkan diambil sebanyak $1 \mathrm{~mL}$ kemudian ditambahkan 2 tetes $\mathrm{FeCl}_{3}$. Terbentuk warna hijau atau hal ini yang menunjukan adanya senyawa fenolik pada sampel. 
Asam galat direaksikan dengan reagen Folin-Ciocalteau akan menghasilkan warna kuning yang menandakan bahwa mengandung fenol, setelah itu ditambahkan dengan larutan $\mathrm{Na}_{2} \mathrm{HCO}_{3}$ menghasilkan warna biru. Intensitas warna biru ditentukan dengan banyaknya kandungan fenol dalam larutan sampel. Semakin besar konsentrasi senyawa fenolik dalam sampel semakin pekat warna biru yang terlihat, penambahan $\mathrm{Na}_{2} \mathrm{HCO}_{3}$ pada uji fenolik bertujuan untuk membentuk suasana basa agar terjadi reaksi reduksi Folin-Ciocalteau oleh gugus hidroksil dari fenolik di dalam sampel (Ismail, Runtuwena dan Fatima, 2012).

Hasil pengukuran absorbansi larutan standar asam galat yang diperoleh dimasukan kedalam microsoft excel untuk mendpatkan kurva kalibrasi larutan standar asam galat berupa grafik kurva konsentrasi (C) versus absorbansi (A). Berdasarkan gambar dapat dilihat bahwa kurva kalibrasi dengan persamaan regresi yaitu $\mathrm{y}=0,0143 \mathrm{x}+0,015$; pada pengukuran absorbansi yang ditunjukan dengan nilai koefisien korelasi (r) sebesar 0,993, nilai (r) ini mendekati angka 1 yang menunjukan bahwa persamaan regresi tersebut adalah linier. Untuk menguatkan data linieritas ini maka dilanjutkan dengan perhitungan $\mathrm{Vx}_{0}$ dan diperoleh nilai $1,39 \%$ $(<5 \%)$ menunjukkan bahwa korelasi yang terbentuk linier.

Pada penelitian ini diperoleh kandungan fenolik total yang ditentukan berdasarkan absorbansi sampel pada instrument spektrofotometer UV-Vis. Diperoleh tiga data dari tiga kali replikasi yaitu 0,567; 0,527 dan 0,526. Selanjutnya data ini dimasukkan dalam perhitungan kadar, sehingga diperoleh kadar fenolik total rata-rata pada ekstrak daun pala sebesar 183,56 mgGAE/g ekstrak.

\section{KESIMPULAN}

Ekstrak etanol daun pala (Myristica fragrans Houtt) mengandung senyawa fenolik total. Kadar fenolik total ekstrak daun pala sebesar 183,56 mgGAE/g ekstrak.

\section{DAFTAR PUSTAKA}

Bimakr, M., 2010, Comparison of Different Extraction Methods for The Extraction of Major Bioactive Flavonoid Compounds from Spearmint (Mentha Spicata L.) Leaves. Food Bioprod Process.1-9.

Fauziah, L., 2008, Studi Dimerisasi Asam. FMIPA, UI: Jakarta.

Hadad, E.A., A. Hamid. 1990, Mengenal berbagai plasma nutfah pala di daerah Maluku Utara.
Balai Penelitian Tanaman Rempah dan Obat, Bogor

Ismail, Jefriyanto, Max R.J Runtuwene, danFeti Fatimah, 2012, Penentuan total fenolik dan uji aktivitas antioksidan pada Biji Dan Kuat Buah Pinang Yaki (Areca vestiaria Giseke). Universitas Sam Ratulangi: Manado

Murtijaya, J., dan Lim Y.Y., 2007, Antioxidant Properties of Phylanthus amarus Extracts as Affected by Different Drying Methods, LWT-Food Sci. Technol.

Puslitbang Perkebunan. 2014. Pendugaan jenis kelamin tanaman pala dengan analisis kandungan myristicin pada daun. InfoTek Perkebunan

Viranda, P.M., 2009, Pengujian Kandungan Ekstrak Buah Tomat (Lycopersicum esculentum var. pyriforme) Secara Spektrofotometri. Fakultas Kedokteran Universitas Indonesia: Jakarta 